\title{
Global Mucormycosis Research: A Bibliometric Assessment Based on Scopus Database (1998-2021)
}

\author{
Brij Mohan Gupta', Ghouse Modin Mamdapur², Saniya Gupta ${ }^{3}$, Latika Rohilla ${ }^{3}$, Devi Dayal ${ }^{3, *}$ \\ ${ }^{1}$ Formerly with CSIR-National Institute of Science, Technology and Development Studies, New Delhi, INDIA. \\ ${ }^{2}$ Information AND Documentation Division, Synthite Industries (Pvt.) Ltd., Kolenchery, Kerala, INDIA. \\ ${ }^{3}$ Department of Pediatrics, Postgraduate Institute of Medical Education and Research, Chandigarh, INDIA.
}

\begin{abstract}
Background: Mucormycosis is an invasive filamentous fungal infection that usually occurs in immunocompromised individuals. Although the disease is well-researched, the assessment of global research on mucormycosis is scarcely reported. Materials and Methods: We used Elsevier's Scopus database to retrieve mucormycosis publications from 1998 to 2021. Using various bibliometric tools, the publication data were analyzed with regard to the growth in the number of publications, their citations, top-yielding organizations and authors, collaborations, and productive journals. Results: One hundred twenty countries contributed 5658 publications to research on mucormycosis. The USA leads with a $30.6 \%$ share, followed by India $(14.1 \%)$, France, Germany, and Spain $(5.4 \%$ to $5.8 \%)$. The annual and absolute growth was $3.9 \%$ and $82.6 \%$; only $11.2 \%$ of publications were funded. The average citations per paper decreased from 28.4 to 11.4 during the two 12-yr periods. The research involved 931 organizations and 1123 authors. The leading organizations were the University of Texas, Anderson Cancer Center, USA, PGIMER-Chandigarh, India, and the University of Paris, France, with 154, 150, and 89 publications. Kontoyiannis, Walsh,
\end{abstract}

and Cornely were the most prolific authors contributing 119, 76, and 58 publications. Mycoses, Clinical Infectious Diseases, and Medical Mycology were the most active journals. Conclusion: The quantity of mucormycosis research increased while the quality decreased during 1998-2021. Fostering collaboration between high- and low-income countries may improve the impact of global mucormycosis research.

Key words: Mucormycosis, Invasive fungal infection, Diabetes, Research output, Scientometrics.

Correspondence

Devi Dayal,

Endocrinology and Diabetes Unit, Department of Pediatrics, Advanced Pediatrics Center, Postgraduate Institute of Medical Education and Research, Chandigarh-160012, INDIA.

Email id: drdevidaya|@gmail.com

DOI: 10.5530/jyp.2021.13.89

\section{INTRODUCTION}

Mucormycosis is an invasive fungal infection (IFI) that causes rapid tissue and angioinvasion and is associated with high morbidity and mortality. ${ }^{1}$ Although it may occur in immunocompetent individuals, certain underlying immunocompromised conditions like diabetes, renal failure, hematological malignancies, iron overload, and immunosuppression particularly predispose patients to mucormycosis. ${ }^{1}$ The most common forms are rhinocerebral, pulmonary, cutaneous, digestive, or disseminated infections, although any organ system may be involved. ${ }^{2-4}$ The outcome largely depends on a multimodal approach that often involves extensive surgical removal of the affected tissues along with the use of antifungals and effective control of the underlying condition..$^{5-7}$

Mucormycosis has presented new global challenges in the last few decades. These include changes in its epidemiology, such as an increase in overall incidence, expansion into new hosts, emergence of new pathogens, and development of multidrug resistance. ${ }^{1,8}$ The global challenges posed by IFI, including mucormycosis, have indeed been recognized by the ECMM, representing 25 affiliated National Medical Mycology Societies. These are reflected in several significant initiatives by ECMM to improve the outcome of these patients worldwide. ${ }^{8}$ The onset of the COVID-19 pandemic has also brought a surge in mucormycosis infections. ${ }^{9}$ To address challenges due to mucormycosis, extensive research appears to have been conducted in several countries. ${ }^{10}$ However, a scientometric assessment of mucormycosis research is scarce. There is only one bibliometric assessment of mucormycosis research that included publications between 1923 and 2021 indexed in the Web of Science (WoS) database. ${ }^{10}$
However, the retrieved publications numbered only 4451, far less than would be expected of an intensely researched topic. ${ }^{10}$ The other bibliometric studies on antifungal resistance and other fungi did not focus on mucormycosis research. ${ }^{11,12}$ Hence, a comprehensive bibliometric analysis of the characteristics and impact of mucormycosis studies is unavailable. In this contribution, we present a qualitative as well as quantitative assessment of global studies on mucormycosis published in the timespan from 1998-2021.

The study aimed to evaluate global research on mucormycosis by retrieving the Scopus-indexed publications from 1998 to 2021. Using select quantitative and qualitative indicators, we analyzed publications growth, the contribution of top 10 countries, the share of international collaboration, financial support, citation metrics, broad subject areas of publications, mapping of important keywords, high-yielding organizations and authors, and their collaborative linkages, productive journals, and characteristics of highly-cited papers (HCP).

\section{MATERIALS AND METHODS}

The mucormycosis publications were retrieved from the Scopus international database (http://www.scopus.com) using a defined search approach similar to our recent bibliometric studies. ${ }^{13-15}$ Briefly, the keywords mucormycosis ${ }^{\star}$ OR zygomycosis ${ }^{\star}$ OR phycomycosis were searched in "TITLE" or "KEY" tags, and the search output was confined to the period '1998-21' using "date range tag". The search string was as

This is an open access article distributed under the terms of the Creative Commons Attribution-NonCommercial-ShareAlike 4.0 License, which allows others to remix, tweak, and build upon the work non-commercially, as long as the author is credited and the new creations are licensed under the identical terms. 
follows: [KEY (mucormycosis ${ }^{*}$ OR zygomycosis ${ }^{\star}$ OR phycomycosis ${ }^{*}$ ) OR TITLE (mucormycosis ${ }^{\star}$ OR zygomycosis* OR phycomycosis ${ }^{\star}$ ) ] AND PUBYEAR > 1997 AND PUBYEAR $<2022$.

The global research data on mucormycosis were further analyzed using Scopus's analytical provisions. Every contributing author or organization covered in multiple authorship publications was fully counted using the complete counting method. The quality of publications was assessed by using indices such as $h$-index (HI), relative citation index (RCI), and citations per paper (CPP). The total number of citations was divided by the total number of publications to obtain CPP. The RCI was calculated by dividing the number of publication's citations by the average number of citations that an article usually receives in the same field. The number so obtained is then benchmarked to the median RCI for all NIH-funded papers. $H$-index or Hirsch index was obtained by Scopus' automated calculators and is defined as the maximum value of $h$ in a way that an author or journal has published at least $h$ papers, and each of those has been cited at least $h$ times. A publication was considered HCP if it had received more than 100 citations. We also used the activity index to understand the gradual changes in research activity with time. The study timespan was divided into two halves of 12-year periods to understand the long-term changes in publication metrics and growth. Citations to the publications were counted from the article's publication until May 22, 2021.

\section{Ethical considerations}

This study used secondary data that does not require approval from the ethics committees meant for human research. We followed all the principles of ethics prescribed for analysis of this nature through respecting citations and ideas and referencing authors and their publications.

\section{RESULTS}

\section{The general profile of publications}

The total publications in mucormycosis research were 5658 . The average annual growth and absolute growths were $3.9 \%$ and $82.6 \%$, respectively. The average CPP was 17.4 , which decreased from 28.4 to 11.4 during the two 12-yr periods (Table 1). Only 11.2\% (637) publications were funded by more than 100 agencies; the funded papers increased almost five times during 1998-2009 to 2010-2021. The average CPP of funded papers was higher than the non-funded papers (37.7 versus 17.4). The leading funding agencies were the National Institute of Health, USA, U.S. Department of Health and Human Service, Pfizer Inc., National Institute of Allergy and Infectious Diseases, and Gilead Sciences, which funded $224,213,138,137$, and 117 papers, respectively. The publication categories were original articles (69.1\%), reviews $(16.7 \%)$, letters $(5.5 \%)$, short notes (3.5\%), conference papers (1.7\%), book chapters (1.0\%), editorials $(0.9 \%)$, short surveys $(0.8 \%)$, erratum $(0.4 \%)$ and undefined $(0.1 \%)$. The studied age groups were as follows: adults (42.1\%), middle-aged (26.1\%), elderly (17.4\%), children (11.2\%), and adolescents (10.3\%).

\section{Researched aspects of mucormycosis}

The largest share of publications was on drug therapy (58.5\%), followed by clinical studies (36.2\%), diagnostics and imaging (16.3\%), complications $(12.3 \%)$, risk factors (9.5\%), epidemiology (9.4\%), pathophysiology (8.7\%), etc. during 1998-21. Publications on epidemiology and risk factors received the highest and the lowest number of citations (average CPP 39.4 and 3.9, respectively).

\section{Type of mucormycosis}

The largest share of publications belonged to unclassified zygomycosis (20.6\%), followed by pulmonary (13.0\%), gastrointestinal (7.8\%), cutaneous (6.6\%), uncommon forms (4.9\%), rhinocerebral (3.2\%), disseminated $(1.6 \%)$ and renal mucormycosis (1.2\%). Publications on gastrointestinal
Table 1: Global publication output on mucormycosis, their citations, and funding during 1998-2021.

\begin{tabular}{ccccc}
\hline Year & $\begin{array}{c}\text { Total } \\
\text { papers }\end{array}$ & Citations & $\begin{array}{c}\text { Citations per } \\
\text { paper }\end{array}$ & $\begin{array}{c}\text { Funded } \\
\text { papers }\end{array}$ \\
\hline 1998 & 104 & 1834 & 17.6 & 0 \\
1999 & 121 & 2675 & 22.1 & 1 \\
2000 & 99 & 2745 & 27.7 & 3 \\
2001 & 121 & 2864 & 23.6 & 2 \\
2002 & 115 & 2851 & 24.7 & 2 \\
2003 & 119 & 3435 & 28.8 & 1 \\
2004 & 161 & 4986 & 30.9 & 6 \\
2005 & 191 & 8666 & 45.3 & 14 \\
2006 & 219 & 6266 & 28.6 & 5 \\
2007 & 223 & 6253 & 28.0 & 13 \\
2008 & 252 & 6385 & 25.3 & 22 \\
2009 & 277 & 7905 & 28.5 & 31 \\
2010 & 276 & 7510 & 27.2 & 25 \\
2011 & 273 & 5764 & 21.1 & 34 \\
2012 & 317 & 6252 & 19.7 & 32 \\
2013 & 296 & 3899 & 13.1 & 35 \\
2014 & 347 & 4679 & 13.4 & 44 \\
2015 & 305 & 3134 & 10.2 & 28 \\
2016 & 300 & 3245 & 10.8 & 34 \\
2017 & 304 & 2575 & 8.4 & 45 \\
2018 & 326 & 2165 & 6.6 & 71 \\
2019 & 392 & 1864 & 4.7 & 86 \\
2020 & 355 & 574 & 1.6 & 75 \\
2021 & 165 & 57 & 0.3 & 28 \\
$1998-2009$ & 2002 & 56865 & 28.4 & 100 \\
$2010-2021$ & 3656 & 41718 & 17.4 & 537 \\
$1998-2021$ & 5658 & 98583 & & \\
\hline & & & 25 & \\
\hline
\end{tabular}

and rhinocerebral forms registered the maximum and the least CPP of 29.2 and 13.6, respectively.

\section{Research by underlying risk factors}

The most commonly studied risk factor was diabetes mellitus contributing $17.4 \%$ of publications, followed by neutropenia (12.4\%), immunocompromised host (10.2\%), hematological malignancy $(7.3 \%)$, corticosteroid therapy (6.1\%), diabetic ketoacidosis $(4.4 \%)$, renal failure $(2.8 \%)$, solid organ transplantation (2.4\%), HIV infection (2.2\%), deferoxamine therapy $(2.1 \%)$, bone marrow transplantation (1.8\%), chronic kidney disease (1.8\%), trauma (1.0\%) and auto-immune disease (0.2\%).

\section{Significant keywords}

We identified 96 keywords from the global literature on mucormycosis, which throw light on the research trends in this field (Figure 1).

\section{Most productive countries}

One hundred twenty countries participated in mucormycosis research. The USA leads in global ranking with a publication share of $30.6 \%$, followed by India (14.1\%), France, Germany, and Spain (5.4\% to 5.8\%), and U.K., Japan, Italy, China, and Australia (2.6\% to $3.9 \%$ share). 
Six countries registered RCI better than the group average of 1.29 (Table 2). The average international collaborative publications (ICP) was $63.8 \%$ (Table 2). All the top 10 countries showed one-to-one collaborative linkages; the largest number of linkages (290, 175, and 146, respectively) were established by the USA, Germany, and France. The country pairs that collaborated the highest number of times were USA-Germany, USA-UK, USA-Spain, USA-France, and USA-India with 51, 44, 44, 43, and 33 linkages, respectively (Figure 2).

\section{Most productive research organizations}

Nine hundred thirty-one organizations participated in global research on mucormycosis. The top 20 organizations produced 60 to 154 publications per organization; together, they contributed $25.0 \%$ (1418 publications) and $69.5 \%$ (68605 citations) to the global publications and citations, respectively. Seven organizations registered their publication output above the group average of 70.9, whereas 12 registered their CPP and RCI above the group average of 48.3 and 2.7, respectively. The scientometric profile of the top 10 most productive and most impactful organizations is shown in Table 3.

All the top 20 organizations showed collaborations; the University of Paris, France, Institut Pastaur Paris, France, and Hopital Necker Enfants Malades, France were the three with the largest collaborative linkages, i.e., 246, 246, and 204 respectively. The organization to organization

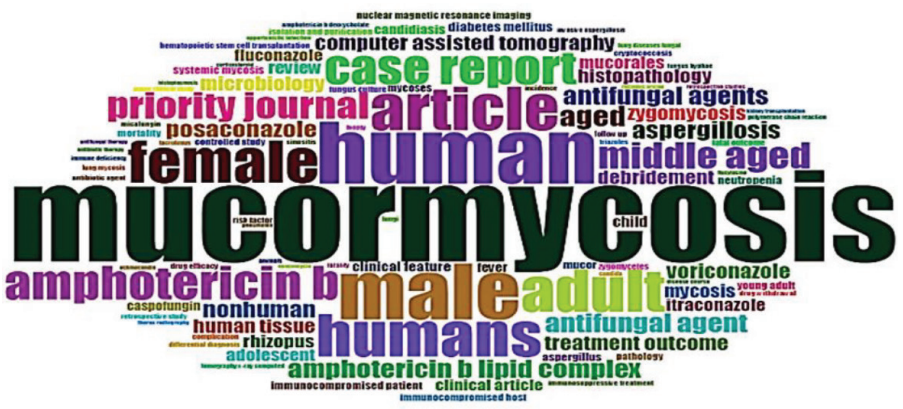

Figure 1: WordCloud portrayal of co-occurrence of significandt keywords in mucormycosis research. The significance of each tag is displayed with text dimension or shading. The greater term implies more noteworthy weight. collaboration was highest between David Geffen School of Medicine at UCLA, USA and University of California, Los Angles, USA (64 linkages), followed by University of Paris, France, and Institut Pastaur Paris (58 linkages), University of Paris, France and Hopital Necker Enfants Malades, France (50 linkages), University of Paris, France and AP-HP Assistance Publique-Hopitaux de Paris, France (47 linkages), etc. (Figure 3).

\section{Most productive authors}

Of the 1123 authors who researched mucormycosis, the top 20 contributed 25 to 119 publications per author. Their share of publications and citations was $15.5 \%$ (877 papers) and $60.1 \%$ (59298 citations) in the global output. The publications output of eight authors was better than the group average of 43.8 , whereas another eight had better CPP and RCI than the group average of 67.6 and 3.8, respectively. Table 4 shows the profile of the top 10 most productive and most impactful authors. Three authors with the largest collaborative linkages (104, 73, and 68) were D.P. Kontoyiannis, T.J. Walsh, and A.S. Ibrahim (Figure 4).

\section{Top journals}

98.5\% (5577) of mucormycosis papers were published in 772 journals; the rest were books, book series, reports, or undefined. The 20 most prolific journals contributed 30 to 187 papers and together accounted for $21.7 \%$ share of global output (Table 5).

\section{Highly cited publications}

3.0\% (173) publications were HCPs; these had received 38708 citations (average CPP 223.7). The USA published a majority of the HCPs (119 publications), followed by France (27 papers), Germany (20 papers), the U.K. (19 papers), Greece (14 papers), Italy (13 papers), India (12 papers), Austria (11 papers), Belgium and Switzerland (10 papers each), etc. The authors from the USA contributed the maximum number of HCPs (Figure 5).

\section{DISCUSSION}

Our bibliometric analysis demonstrates that global mucormycosis research showed impressive growth during the last about two decades. However, the research quality as judged by the CPP showed a decline

Table 2: Most productive countries in global mucormycosis research during 1998-2021.

\begin{tabular}{|c|c|c|c|c|c|c|c|c|c|}
\hline \multirow[t]{2}{*}{ S.no. } & \multirow[t]{2}{*}{ Country } & \multicolumn{3}{|c|}{ Total number and share (\%) of publications } & TC & CPP & ICP & ICP\% & $\mathrm{RCl}$ \\
\hline & & 1998-2009 & $2010-2021$ & $1998-2021$ & \multicolumn{5}{|c|}{$1998-2021$} \\
\hline 1 & USA & $639(31.9)$ & $1097(30.0)$ & $1736(30.6)$ & 52966 & 30.5 & 358 & 56.0 & 1.7 \\
\hline 2 & India & $213(10.6)$ & $586(16.0)$ & $799(14.1)$ & 7711 & 9.6 & 70 & 32.8 & 0.5 \\
\hline 3 & France & $105(5.2)$ & $228(6.2)$ & $333(5.8)$ & 9773 & 29.3 & 94 & 89.5 & 1.6 \\
\hline 4 & Germany & $104(5.1)$ & 209 (5.7) & $313(5.5)$ & 7741 & 24.7 & 134 & 128.8 & 1.4 \\
\hline 5 & Spain & $108(5.3)$ & $201(5.5)$ & $309(5.4)$ & 2149 & 6.9 & 15 & 13.8 & 0.4 \\
\hline 6 & U.K. & $62(3.1)$ & $160(4.3)$ & 222 (3.9) & 6298 & 28.3 & 108 & 174.1 & 1.6 \\
\hline 7 & Japan & $84(4.2)$ & $122(3.3)$ & $206(3.6)$ & 2331 & 11.3 & 24 & 28.5 & 0.6 \\
\hline 8 & Italy & $66(3.3)$ & $135(3.6)$ & $201(3.5)$ & 5877 & 29.2 & 62 & 93.9 & 1.6 \\
\hline 9 & China & $34(1.7)$ & $156(4.2)$ & $190(3.3)$ & 1467 & 7.7 & 34 & 100.0 & 0.4 \\
\hline 10 & Australia & $59(2.9)$ & $93(2.5)$ & $152(2.6)$ & 3614 & 23.7 & 42 & 71.1 & 1.3 \\
\hline \multicolumn{2}{|c|}{ Total of 10} & $1474(73.6)$ & $2987(81.7)$ & $4461(78.8)$ & 99927 & 22.4 & 941 & 63.8 & 1.2 \\
\hline \multicolumn{2}{|c|}{ Global total } & 2002 & 3656 & 5658 & 98583 & 17.4 & -.- & --- & --- \\
\hline
\end{tabular}

Abbreviations: TC, total citations; CPP, citations per paper; ICP, international collaborative papers; RCI, relative citation index. 
during the second 12-year time period. This observation is consistent with a decrease in the medical research quality in general during the last few decades due to several factors, such as a substantial increase in the number of researchers and the priority given to quantity and not quality during hiring or job promotions. ${ }^{16}$ Surprisingly, the decline in the mucormycosis research quality was noted despite a 3 -fold increase in the proportion of funded publications (4.9\% to $14.6 \%)$ and an overall better CPP of funded publications (37.7 versus 17.4). This observation indicates that even the better funding support during the latter half of

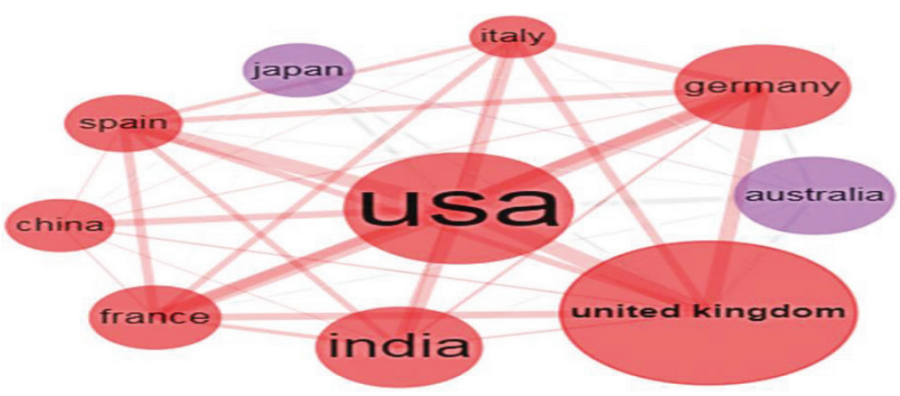

Figure 2: Collaboration network of the 10 countries generated form the Boblioshiny app. The countries with the same colour belong to a single cluster. The thickness of the links berween the countries and the distance between them represents the degree of their research collaboration. The bigger the diameter of a nerwork node and its font size, the bigger its weight in research collaboration. the study span was unable to sustain the previous high quality of mucormycosis research and is contrary to the generally accepted view that research funding is an important determinant of citations and impact. ${ }^{16-18}$ In a recent study, we observed a considerable difference between the CPP of non-funded and funded publications (18.6 versus 77.2$).{ }^{19}$

The mucormycosis research is dominated by high-income countries in the North-American and Western-European regions, an observation noted in several previous scientometric studies. ${ }^{20-22}$ Such high productivity and quality result from the availability of financial support and commitment to research by the national governments. Additionally, the high-income countries provide the infrastructure and funding required for conducting such highly organized research activity. ${ }^{17}$ Among the

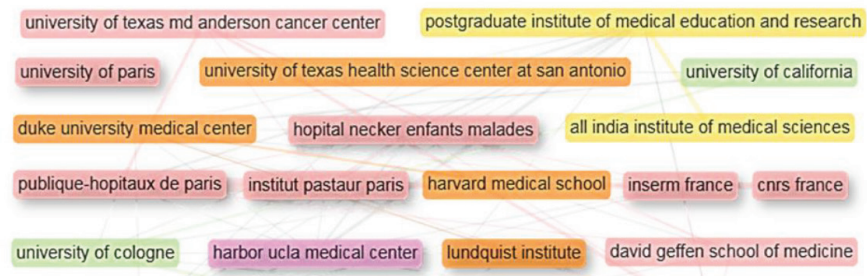

medical university of innsbruck national and kapodistrian university of athens

Figure 3: Collaboration network of the top 20 organizations in mucormycosis research. Six groups are represented with different colours. The box size and text dimension of every hub are relative to its distribution output in the same field.

Table 3: Top ten most productive and most impactful organizations in global mucormycosis research during 1998-2021.

\begin{tabular}{|c|c|c|c|c|c|c|c|c|}
\hline S.no. & Organization & TP & TC & CPP & $\mathrm{HI}$ & ICP & ICP\% & $\mathrm{RCl}$ \\
\hline \multicolumn{9}{|c|}{ Top 10 most productive organizations } \\
\hline 1 & University of Texas MD Anderson Cancer Center, USA & 154 & 12018 & 78.0 & 48 & 62 & 40.2 & 4.4 \\
\hline 2 & Postgraduate Institute of Medical Education and Research, Chandigarh, India & 150 & 2946 & 19.6 & 29 & 22 & 14.6 & 1.1 \\
\hline 3 & University of Paris, France & 89 & 3913 & 43.9 & 32 & 31 & 34.8 & 2.5 \\
\hline 4 & Institut Pastaur Paris, France & 78 & 3472 & 44.5 & 29 & 30 & 38.4 & 2.5 \\
\hline 5 & David Geffen School of Medicine at UCLA, USA & 76 & 4650 & 61.1 & 33 & 17 & 22.3 & 3.5 \\
\hline 6 & University of California, Los Angles, USA & 73 & 4825 & 66.1 & 31 & 17 & 23.2 & 3.7 \\
\hline 7 & University of Texas Health Science Center at San Antonio, USA & 72 & 3559 & 49.4 & 30 & 31 & 43.0 & 2.8 \\
\hline 8 & AP-HP Assistance Publique-Hopitaux de Paris, France & 67 & 2099 & 31.3 & 25 & 19 & 28.3 & 1.8 \\
\hline 9 & All India Institute of Medical Sciences, New Delhi, India & 66 & 524 & 7.9 & 12 & 2 & 3.0 & 0.4 \\
\hline 10 & Duke University Medical Center, USA & 61 & 3405 & 55.8 & 28 & 22 & 36.0 & 3.2 \\
\hline \multicolumn{9}{|c|}{ Top 10 most impactful organizations } \\
\hline 1 & University of Texas MD Anderson Cancer Center, USA & 154 & 12018 & 78.0 & 48 & 62 & 40.2 & 4.4 \\
\hline 2 & Harbor UCLA Medical Center, Los Angles Biomedical Center, USA & 52 & 3468 & 66.6 & 29 & 18 & 34.6 & 3.8 \\
\hline 3 & University of California, Los Angles, USA & 73 & 4825 & 66.1 & 31 & 17 & 23.2 & 3.7 \\
\hline 4 & National and Kabedistrian University of Athens, Greece & 53 & 3439 & 64.8 & 27 & 35 & 66.0 & 3.7 \\
\hline 5 & Medizinische Universitat Innsbruck, Austria & 54 & 3322 & 61.5 & 27 & 40 & 74.0 & 3.5 \\
\hline 6 & David Geffen School of Medicine at UCLA, USA & 76 & 4650 & 61.1 & 33 & 17 & 22.3 & 3.5 \\
\hline 7 & The Lundquist Institute, USA & 52 & 3054 & 58.7 & 27 & 14 & 26.9 & 3.3 \\
\hline 8 & Hopital Necker Enfants Malades, France & 60 & 3384 & 56.4 & 26 & 19 & 31.67 & 3.2 \\
\hline 9 & Duke University Medical Center, USA & 61 & 3405 & 55.8 & 28 & 22 & 36.0 & 3.2 \\
\hline 10 & Aristotle University of Thessaloni, Greece & 53 & 2893 & 54.5 & 24 & 37 & 69.8 & 3.1 \\
\hline
\end{tabular}

Abbreviations: TP, total publications; TC, total citations; CPP, citations per paper; HI, Hirsch-index; ICP, international collaborative papers; RCI, relative citation index. 
Table 4: Top 10 most productive and most impactful authors in global mucormycosis research.

\begin{tabular}{|c|c|c|c|c|c|c|c|c|}
\hline S.no. & Author & Affiliation & TP & $\mathrm{TC}$ & CPP & $\mathrm{HI}$ & ICP (\%) & $\mathrm{RCI}$ \\
\hline \multicolumn{9}{|c|}{ Top 10 most productive authors } \\
\hline 1 & D.P. Kontoyiannis & University of Texas MD Anderson Cancer Center, USA & 119 & 10879 & 91.4 & 46 & $48(40.3)$ & 5.2 \\
\hline 2 & T.J.Walsh & National Cancer Institute, USA & 76 & 7789 & 102.4 & 33 & $35(46.0)$ & 5.8 \\
\hline 3 & O.A.Cornely & University of Colgne, Germany & 58 & 2303 & 39.7 & 23 & $29(50.0)$ & 2.2 \\
\hline 4 & A.S. Ibrahim & David Geffen School of Medicine at UCLA, USA & 57 & 3580 & 62.8 & 30 & $14(24.5)$ & 3.6 \\
\hline 5 & O. Lortholary & University of Paris, France & 50 & 3476 & 69.5 & 26 & $15(30.0)$ & 3.9 \\
\hline 6 & E. Rollides & Aristotle University of Thessaloni, Greece & 50 & 2945 & 58.9 & 24 & $37(74.0)$ & 3.3 \\
\hline 7 & A.Chakrabarti & $\begin{array}{c}\text { Postgraduate Institute of Medical Education and Research, } \\
\text { Chandigarh, India }\end{array}$ & 47 & 1831 & 38.9 & 21 & $14(29.7)$ & 2.2 \\
\hline 8 & R.E. Lewis & University of Texas MD Anderson Cancer Center, USA & 45 & 3195 & 71.0 & 25 & $24(53.3)$ & 4.0 \\
\hline 9 & C. Lass-Florl & Medizinische Universitat Innsbruck, Austria & 40 & 2615 & 65.3 & 23 & $29(72.5)$ & 3.7 \\
\hline 10 & F. Lanternier & University of Paris, France & 35 & 1983 & 56.6 & 18 & $5(14.2)$ & 3.2 \\
\hline \multicolumn{9}{|c|}{ Top 10 most impactful authors } \\
\hline 1 & B. Spellberg & University of California, Los Angles, USA & 34 & 3986 & 117.2 & 28 & $5(14.7)$ & 6.7 \\
\hline 2 & T.J.Walsh & National Cancer Institute, USA & 76 & 7789 & 102.4 & 33 & $35(46.0)$ & 5.8 \\
\hline 3 & L. Pagano & Universita Ca Holica, Italy & 28 & 2758 & 98.5 & 16 & $11(39.2)$ & 5.6 \\
\hline 4 & D.P. Kontoyiannis & University of Texas MD Anderson Cancer Center, USA & 119 & 10879 & 91.4 & 46 & $48(40.3)$ & 5.2 \\
\hline 5 & A.H. Groll & Universitat Klinikum Munster, Germany & 26 & 1887 & 72.5 & 18 & $20(76.9)$ & 4.1 \\
\hline 6 & R.E. Lewis & University of Texas MD Anderson Cancer Center, USA & 45 & 3195 & 71.0 & 25 & $24(53.3)$ & 4.0 \\
\hline 7 & O. Lortholary & University of Paris, France & 50 & 3476 & 69.5 & 26 & $15(30.0)$ & 3.9 \\
\hline 8 & R.Herbrecht & Hopital de Hautepierre, France & 34 & 2302 & 67.7 & 20 & $13(38.2)$ & 3.8 \\
\hline 9 & C. Lass-Florl & Medizinische Universitat Innsbruck, Austria & 40 & 2615 & 65.3 & 23 & $29(72.5)$ & 3.7 \\
\hline 10 & A.S. Ibrahim & David Geffen School of Medicine at UCLA, USA & 57 & 3580 & 62.8 & 30 & $14(24.5)$ & 3.6 \\
\hline
\end{tabular}

Abbreviations: TP, total publications; TC, total citations; CPP, citations per paper; HI, Hirsch Index; ICP, international collaborative publications; RCI, relative citations index.

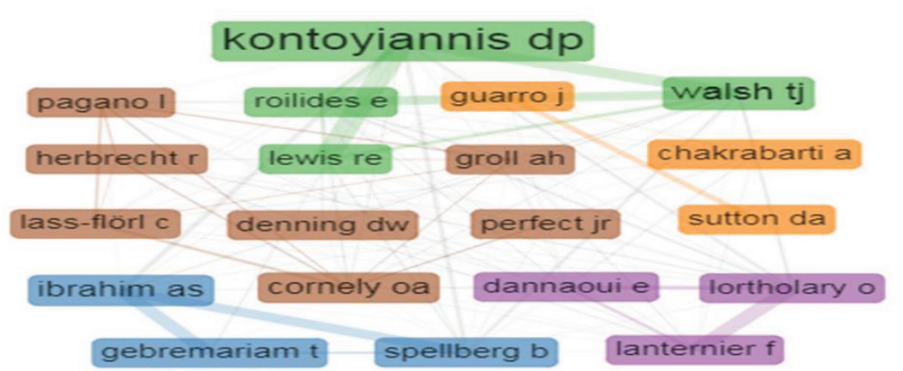

Figure 4: Collaboration network of top 20 authors grouped into five cluster comparising of 4 (cluster 1 ), 3 each (cluster 2, 3, and 4) and 7 authors (cluster 5 ).

low-income countries, only India figures in the list of top 10 countries partly due to collaborative research initiatives of a few dedicated organizations and researchers in fungal diseases. ${ }^{8,23}$ In general, the paucity of research funding and infrastructure in low-income countries hinders impactful research. ${ }^{18}$ The wide disparity in mucormycosis research between high-income and low-income countries needs to be addressed through supportive research endeavors and collaborations. ${ }^{24}$ The highincome countries, their organizations, and researchers should strengthen research collaboration with their counterparts in low-income countries to improve long-term impact and sustainability in global mucormycosis research. ${ }^{24}$ In the present study, too, the research partnerships between high- and low-income countries were far fewer than those amongst high-income countries.
We used a single database similar to the previous bibliometric analyses. ${ }^{20,21,25}$ Therefore, our study may not have captured all publications or citations. Some authors have suggested conducting a simultaneous search in PubMed, Scopus, and WoS, but some data may still be missed. ${ }^{26,27}$ Despite the limitation of using a single database, our study could identify the research lacunae and trends in mucormycosis research. ${ }^{28}$ Thus, the study provides the global architecture of research in mucormycosis and a framework for authors, organizations, and countries to develop focus and collaborations on further research in this area.

\section{CONCLUSION}

The North-American and Western-European countries dominate the mucormycosis research landscape, and a wide gap exists between highand low-income countries. The quantity of mucormycosis research has increased during 1998-2021, but the quality has suffered despite better funding over the last decade. It is necessary to increase collaboration between high- and low-income countries to improve the impact and sustainability of global mucormycosis research.

\section{Contributors' List}

BMG, Concept, and design of the study, and acquisition, analysis, and interpretation of data; GMM, Data analysis, and intellectual inputs during the revision of the manuscript; SG and LR, Important intellectual inputs during manuscript preparation; DD, Manuscript preparation and critical revision for important intellectual content. All authors approved the final version of the manuscript. 
Table 5: Leading journals that published mucormycosis research during 1998-2021.

\begin{tabular}{|c|c|c|c|c|c|c|}
\hline \multirow{3}{*}{$\begin{array}{c}\text { S.no. } \\
1\end{array}$} & \multirow{3}{*}{$\begin{array}{l}\text { Journal } \\
\text { Mycoses }\end{array}$} & \multicolumn{3}{|c|}{ Total papers } & Cited & $\mathrm{CPP}^{*}$ \\
\hline & & \multirow{2}{*}{$\frac{1998-2009}{55}$} & \multirow{2}{*}{$\frac{2010-2021}{132}$} & \multirow{2}{*}{$\frac{1998-2021}{187}$} & \multicolumn{2}{|c|}{$1998-2021$} \\
\hline & & & & & 3163 & 16.9 \\
\hline 2 & Clinical Infectious Diseases & 52 & 44 & 96 & 12413 & $129.3^{*}$ \\
\hline 3 & Medical Mycology & 34 & 57 & 91 & 2103 & $23.1^{*}$ \\
\hline 4 & Clinical Microbiology and Infection & 35 & 37 & 72 & 4194 & $58.2^{*}$ \\
\hline 5 & Mycopathologia & 11 & 60 & 71 & 520 & 7.3 \\
\hline 6 & Antimicrobial Agents and Chemotherapy & 28 & 41 & 69 & 3823 & $55.4^{*}$ \\
\hline 7 & Journal of Clinical Microbiology & 29 & 40 & 69 & 2429 & $35.2^{*}$ \\
\hline 8 & Current Fungal Infection Reports & 5 & 58 & 63 & 395 & 6.2 \\
\hline 9 & Medical Mycology Case Reports & 0 & 61 & 61 & 182 & 2.9 \\
\hline 10 & Transplant Infectious Disease & 17 & 42 & 59 & 1168 & 19.8 \\
\hline 11 & Journal De Mycologie Medicale & 13 & 42 & 55 & 273 & 4.9 \\
\hline 12 & BMJ Case Reports & 2 & 50 & 52 & 119 & 2.2 \\
\hline 13 & Journal of Antimicrobial Chemotherapy & 8 & 35 & 43 & 1842 & $42.8^{*}$ \\
\hline 14 & Revista Iberoamericana De Micologia & 5 & 32 & 37 & 291 & 7.8 \\
\hline 15 & Journal of Fungi & 0 & 34 & 34 & 250 & 7.3 \\
\hline 16 & Infectious Diseases in Clinical Practice & 11 & 22 & 33 & 41 & 1.2 \\
\hline 17 & Indian Journal of Otolaryngology and Head and Neck Surgery & 12 & 19 & 31 & 102 & 3.2 \\
\hline 18 & Transplant Proceedings & 10 & 21 & 31 & 187 & 6.0 \\
\hline 19 & Bone Morrow Transplantation & 21 & 9 & 30 & 884 & $29.4^{*}$ \\
\hline \multirow[t]{2}{*}{20} & Pediatric Infectious Disease Journal & 12 & 18 & 30 & 704 & $23.4^{*}$ \\
\hline & Total of top 20 journals & 360 & 854 & 1214 & 35083 & 28.9 \\
\hline
\end{tabular}

${ }^{\star} \mathrm{CPP}=$ citations per paper; ${ }^{*}$ most impactful journals

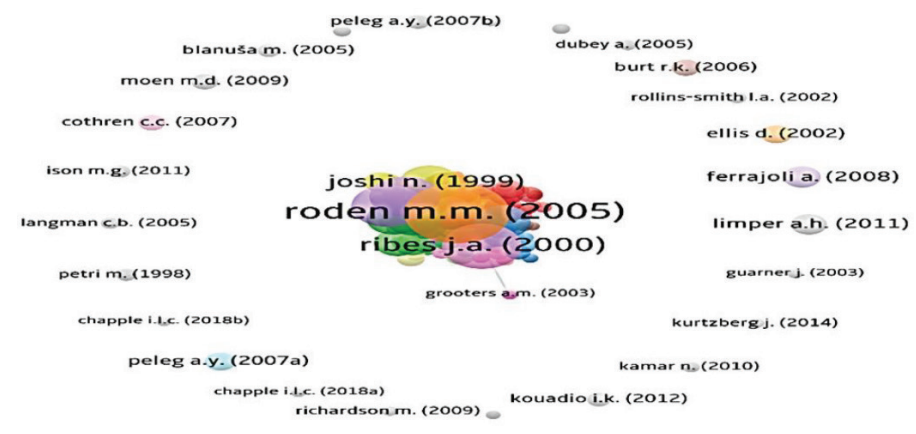

Figure 5: Network visualization of the top 173 highly-cited papers grouped into 38 cluster. The size of the nodes represents the number of citations.

\section{CONFLICT OF INTEREST}

The authors declare that there is no conflict of interest.

\section{ABBREVIATIONS}

ECMM: European Confederation of Medical Mycology; COVID-19: The Coronavirus Disease of 2019.

\section{REFERENCES}

1. Prakash $\mathrm{H}$, Chakrabarti A. Global epidemiology of mucormycosis. J Fungi (Basel). 2019;5(1):26. doi: 10.3390/jof5010026, PMID 30901907.

2. Dayal D, Jain P, Kumar R, Bakshi J, Menon P, Das A, et al. Clinical spectrum and outcome of invasive filamentous fungal infections in children with Type 1 diabetes: North Indian experience. Clin Pediatr Endocrinol. 2015;24(2):51-7. doi: 10.1297/cpe.24.51, PMID 26019401.

3. Devidayal, Menon P, Vaiphei K, Singh M, Rao K, Singhi S. Pleuropulmonary Zygomycosis in a diabetic child. Clin Pediatr Endocrinol. 2009:18(1):35-40. doi: 10.1297/cpe.18.35, PMID 24790378.

4. Dayal D, Saini AG, Sodhi K, Rao K, Gupta N, Dogra S. Thymic Zygomycosis in a Girl with Poorly Controlled Diabetes. Acta Endo (Buc). 2011;7(3):379-83. doi: 10.4183/aeb.2011.379.

5. Dayal D. A multimodal approach is necessary to manage mucormycosis in patients with diabetes. J Clin Diagn Res. 2016;10(9):SL01. doi: 10.7860/ JCDR/2016/21349.8477, PMID 27790541.

6. Dayal D, Bakshi J. Early diagnosis and surgery is crucial to survival outcome in rhinocerebral mucormycosis. Indian J Otolaryngol Head Neck Surg. 2016;68(2):261-2. doi: 10.1007/s12070-015-0953-1, PMID 27340648.

7. Dayal D, Bakshi J, Jain P, Shivaprakash MR, Singhi S. Outcome of rhino-sinus mucormycosis in children with Type 1 diabetes. Indian J Pediatr. 2015;82(7):651-2. doi: 10.1007/s12098-014-1680-4, PMID 25589195.

8. Hoenigl M, Gangneux JP, Segal E, Alanio A, Chakrabarti A, Chen SC, et al. Global guidelines and initiatives from the European Confederation of Medical Mycology to improve patient care and research worldwide: new leadership is about working together. Mycoses. 2018;61(11):885-94. doi: 10.1111/myc.12836 PMID 30086186.

9. Pal R, Singh B, Bhadada SK, Banerjee M, Bhogal RS, Hage N, Kumar A. COVID-19-associated mucormycosis: an updated systematic review of literature. Mycoses. 2021 Jun 16. doi: 10.1111/myc.13338 [Epub ahead of print]. PMID 34133798.

10. Sivankalai S, Sivasekaran K. Mucormycosis (Black Fungus) Maiming Covid Patients: scientometrics analysis through prism of Biblioshiny. Libr Philos Pract. 2021;5546.

11. Sweileh WM, Sawalha AF, Al-Jabi S, Zyoud SH. Bibliometric analysis of literature on antifungal triazole resistance: 1980-2015. GERMS. 2017;7(1):19-27. doi: 10.18683/germs.2017.1104, PMID 28331838

12. Ramirez-Malule H, López-Agudelo V, Gómez-Ríos D. Candida auris: a bibliometric analysis of the first ten years of research (2009-2018). J app pharm sci. 2020;10(3):12-21. doi: 10.7324/JAPS.2020.103002.

13. Dayal D, Gupta BM. Pediatric hyperthyroidism research: A scientometric assessment of global publications during 1990-2019. Thyroid Res Pract. 
2020;17(3):134-40. doi: 10.4103/trp.trp_67_20.

14. Gupta BM, Dayal D. Pediatric type 1 diabetes research in the 21 st century: a scientometric review. Pediatr Endocrinol Diabetes Metab. 2020;26(3):132-9 doi: 10.5114/pedm.2020.98165, PMID 32901470

15. Dayal D, Gupta BM, Gupta S. Quantitative and qualitative assessment of Indian research yield in type 1 diabetes during 1996-2019. J Diabetol. 2021;12(1):28-35

16. Sandström U, van den Besselaar P. Quantity and/or Quality? The Importance of publishing Many Papers. PLOS ONE. 2016;11(11):e0166149. doi: 10.1371/ journal.pone.0166149, PMID 27870854.

17. Fradkin JE, Wallace JA, Akolkar B, Rodgers GP. Type 1 diabetes-reaping the rewards of a targeted research investment. Diabetes. 2016;65(2):307-13. doi: 10.2337/db15-1030, PMID 26798117.

18. Lakhotia SC. Research fund crunch, real or created, is hitting India's Academia on the Wrong Side. Proc Indian Natl Sci Acad. 2018;98(3):545-7. doi: 10.16943/ ptinsa/2018/49475.

19. Gupta BM, Sikka P, Gupta S, Dayal D. Indian research in gestational diabetes mellitus during the past three decades: A scientometric analysis. J Obstet Gynaecol India. 2021;71(3):254-61. doi: 10.1007/s13224-021-01444-7, PMID 34408344

20. Dayal D, Gupta BM, Raviteja KV, Pal R, Dhawan SM. Research on Type 2 diabetes in India during 1982 to 2019: A comprehensive bibliometric assessment. J Diabetol. 2021.

21. Dayal D, Gupta BM, Gupta A. Thyroid disorders in children and adolescents: systematic mapping of global research over the last three decades. Thyroid Res
Pract. 2021 Aug 14. doi: 10.4103/trp.trp_5_21 [Epub ahead of print].

22. Brüggmann $D$, Richter $T$, Klingelhöfer $D$, Gerber $A$, Bundschuh $M$, Jaque J, et al. Global architecture of gestational diabetes research: density-equalizing mapping studies and gender analysis. Nutr J. 2016;15:36. doi: 10.1186/s12937016-0154-0, PMID 27044432.

23. Rudramurthy SM, Hoenigl M, Meis JF, Cornely OA, Muthu V, Gangneux JP, et al. ECMM/ISHAM recommendations for clinical management of COVID -19 associated mucormycosis in low- and middle-income countries. Mycoses. 2021:64(9):1028-37. doi: 10.1111/myc.13335, PMID 34133816.

24. Haregu TN, Byrnes A, Singh K, Sathish T, Pasricha N, Wickramasinghe K, et al. A scoping review of non-communicable disease research capacity strengthening initiatives in low and middle-income countries. Glob Health Res Policy. 2019;4:31. doi: 10.1186/s41256-019-0123-1, PMID 31799408.

25. Gupta BM, Pal R, Rohilla L, Dayal D. Bibliometric analysis of diabetes research in relation to the COVID-19 pandemic. J Diabetol. 2021.

26. Kokol P, Vošner HB. Discrepancies among Scopus, Web of Science, and PubMed coverage of funding information in medical journal articles. J Med Libr Assoc. 2018;106(1):81-6. doi: 10.5195/jmla.2018.181, PMID 29339937.

27. AlRyalat SAS, Malkawi LW, Momani SM. Comparing bibliometric analysis using PubMed, Scopus, and Web of Science databases. J Vis Exp. 2019;152(152):e58494. doi: 10.3791/58494, PMID 31710021.

28. Perryman CL. Mapping studies. J Med Libr Assoc. 2016;104(1):79-82. doi: 10.3163/1536-5050.104.1.014, PMID 26807059.

Article History: Received: 28-08-2021; Revised: 31-09-2021; Accepted: 04-11-2021.

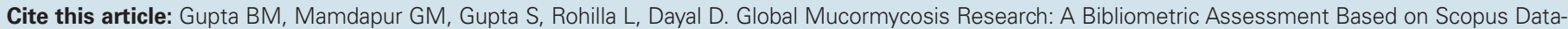
base (1998-2021). J Young Pharm. 2021;13(4):356-62. 